\title{
Research on microstructure and mechanical properties of explosively welded stainless steel/commercially pure Ti plate
}

\author{
Marcin Małek ${ }^{1, *}$, Marcin Wachowski ${ }^{2}$, and Robert Kosturek ${ }^{2}$ \\ ${ }^{1}$ Military University of Technology, Faculty of Civil Engineering and Geodesy, 2 Gen. Sylwestra Kaliskiego Str., \\ 00-908 Warsaw, Poland \\ 2 Military University of Technology, Faculty of Mechanical Engineering, 2 Gen. Sylwestra Kaliskiego Str., \\ 00-908 Warsaw, Poland
}

Received: 7 November 2019 / Accepted: 8 December 2019

\begin{abstract}
Surface protection by the application of explosive welding is one of the meaningful methods used in many chemical devices like reactor condensers, heat exchangers, steam turbines and other processing apparatus. Due to the wide range of explosively welded applications, the problem of the useful lifetime of the products obtained by this method becomes important and should be well understood. Process of explosive welding is related to enormous pressure and high detonation velocity, which causes intense energy release in a short time, which favors to produce solid wavy bond featured with high metallurgical quality. Due to strain hardening in the bond zone, significant changes in microstructures and mechanical properties were observed. In this paper, 316L stainless steel explosively welded with commercially pure titanium was investigated to show the correlations and changes between microstructures and mechanical properties before and after annealing. Application of postweld heat treatment contributes to stress relieving and improves the mechanical properties, which is closely related to microstructure recrystallization and hardness decrease adjacent to joint.
\end{abstract}

Keywords: Cladding / explosive welding / joining / microstructure

\section{Introduction}

The problem of the surface protection is one of the most important subjects in the production of modern engineering structures, due to increasing demands in the area of efficiency, strength, reliability and fatigue life of required applications. Often surface protection is realized by coatings, but due to different chemical composition and structure of the connected materials, sometimes joining process is impossible to carry out by conventional welding or bonding methods [1-3]. This problem can be solved by using an explosive welding method which is one of the most effective technical engineering processes among joining methods because is used to join a wide variety of similar or different metals like steel and titanium [4]. The main advantage of this process is a possibility to optimize the performance of the composite for high temperature, cryogenic, high strength, thermal or electrical conductivity, enhanced mechanical properties, corrosion resistance, or any other applications [5]. Joining by explosion belongs to a group of pressure welding and it is often used method due to many benefits like: possibility to join different materials with each other in one process; minimum

\footnotetext{
* e-mail: marcin.wachowski@wat.edu.pl
}

diffusion rate of bonded metals, the simplicity of process, possibility to join large size of connected elements and a wide range of base and cladding material thickness [6].

Carrying out of the explosive welding is not a complicated method what can significantly reduce the cost of the bimetallic production. Because of the numerous advantages, explosive welding method is used to produce pipes, tubes, chemical process vessels and many applications in shipbuilding and cryogenic industry but major areas using of this method are applications in power plants like heat exchanger tube sheets, pressure vessels and steam condensers [6-8]. Due to many applications of items produced by explosive welding, focusing on the metallographic and mechanical aspect of materials after the welding is important. Previous investigations revealed significant changes in microstructures explosively welded plates [9]. Due to changes in mechanical and chemical properties near the interface, applied of the heat treatment is necessary, hence microstructures and mechanical properties of bimetal in state after the cladding and state after the annealing are investigated in detail. Experimental work in this paper is focused on the study of influence the post-heat treatment on microstructure and mechanical properties of explosively welded austenitic stainless steel $316 \mathrm{~L}$ with commercially pure titanium, which is used to produce the sieve trays of heat exchangers (Fig. 1). For 


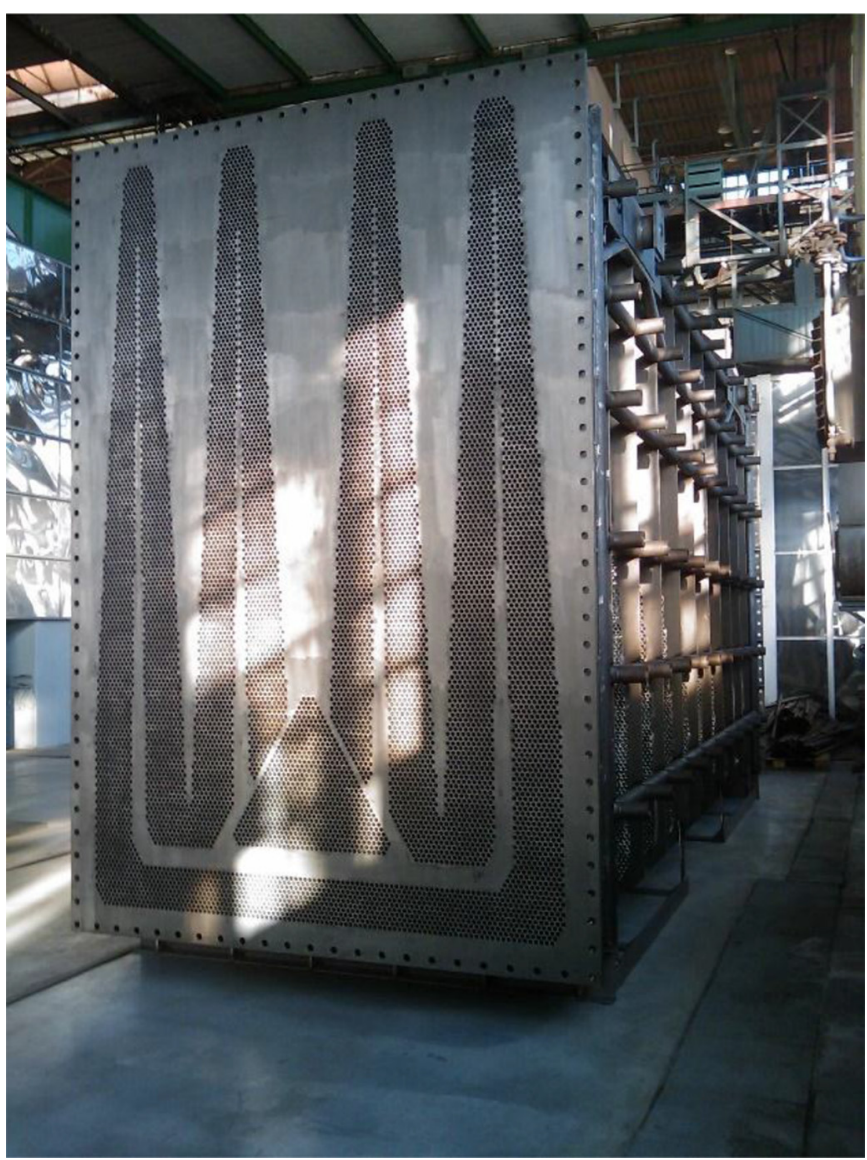

Fig. 1. Heat exchanger with sieve tray.

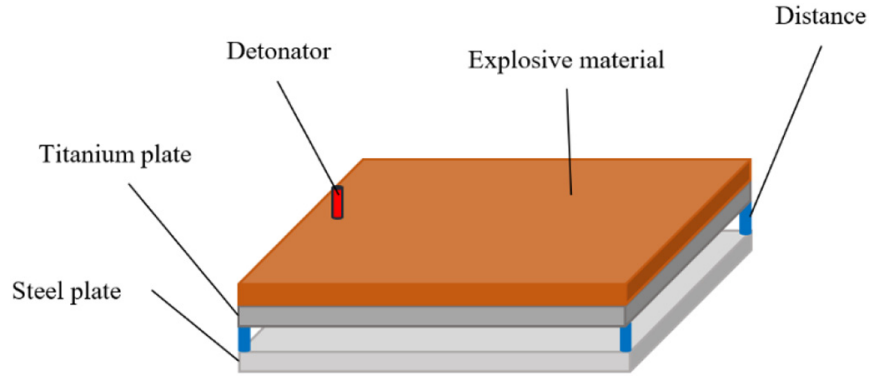

Fig. 2. Scheme of the explosive welding system.

analysis microstructures, methods of light and scanning electron microscopy were used, supplemented by microhardness and three-points bending tests.

\section{Experimental}

For this study, investigated 316L stainless steel plate explosively welded with commercially pure titanium was provided by EXPLOMET company. The scheme of the explosive welding system is shown in Figure 2. Type of explosive used during the process was ANFO (ammonium nitrade fuel oil). Thickness of the explosive layer was $50 \mathrm{~mm}$ while initial position angle between plates was $0^{\circ}$. Impact angle was $9^{\circ}$ and impact velocity was $460 \mathrm{~m} / \mathrm{s}$.
Table 1. Chemical composition of titanium.

\begin{tabular}{llcll}
\hline $\mathrm{Fe}$ & $\mathrm{O}$ & $\mathrm{N}$ & $\mathrm{C}$ & $\mathrm{Ti}$ \\
\hline & \multicolumn{4}{c}{ weight $]$} \\
0.04 & 0.04 & 0.01 & 0.02 & Rest \\
\hline
\end{tabular}

Table 2. Chemical composition of 316L.

\begin{tabular}{llllll}
\hline $\mathrm{C}$ & $\mathrm{Cr}$ & $\mathrm{Mn}$ & $\mathrm{Mo}$ & $\mathrm{Ni}$ & $\mathrm{Fe}$ \\
\hline \multicolumn{5}{c}{$[\%$ weight $]$} \\
0.03 & 16.67 & 1.24 & 2.10 & 10.08 & Rest \\
\hline
\end{tabular}

Detonation velocity was equal to $2700 \mathrm{~m} / \mathrm{s}$. Before joining surfaces of the joined materials were polished and cleaned by acetone. Bimetal has dimensions $500 \times 700 \mathrm{~mm}$ wherein $316 \mathrm{~L}$ sheet with a thickness of $10 \mathrm{~mm}$ was used as a base material, while pure titanium sheet with a thickness of $6 \mathrm{~mm}$ was used as a flyer plate. Chemical compositions of welded plates are shown in Tables 1 and 2 , respectively. To investigate the influence of the heat treatment on the bimetal, applied post-heat treatment was performed in temperature $600{ }^{\circ} \mathrm{C}$ for $90 \mathrm{~min}$ with cooling in a furnace to $300{ }^{\circ} \mathrm{C}$ and then in still air to environmental conditions.

To show the differences in the microstructures of the material before and after the heat treatment, metallographic investigations were carried out. Samples for microstructures observations were cut from bimetal in a parallel direction relative to joining direction. To reveal the titanium microstructures, samples were ground, polished using $0.6 \mu \mathrm{m} \mathrm{Al}_{2} \mathrm{O}_{3}$ powder and etched in lactic and nitric acid with hydrofluoric acid and in distilled water solution according to P. Tamilchelvan investigations [3]. According to R. Kacar research, stainless steel microstructures were revealed using the nital and following oxalic acid solutions in distilled water [10]. Metallographic observations of parent and flyer plates and the interface was carried out using the digital light microscope Keyence VHX-600. To examining the chemical composition zone adjacent to interface, scanning electron microscope (SEM) Hitachi SU-70 with energy-dispersive X-ray spectroscopy (EDS) and back-scattered electron (BSE) detector was used. Microhardness measurements were performed across the joint boundary using Vickers microhardness tester with $100 \mathrm{~g}$ load and interval of $50 \mu \mathrm{m}$ both in steel and titanium side. To define the mechanical properties of bimetal in the state before and after heat treatment, three points bending tests with cyclic loads were carried out according to ASTM A263-94a standard [11].

\section{Results}

Depending on impact velocity reached during the welding process, the interface can reveal wavy or smooth morphology. In the case of studied bimetal, velocity reached $2300 \mathrm{~m} / \mathrm{s}$ what caused a smooth morphology, 


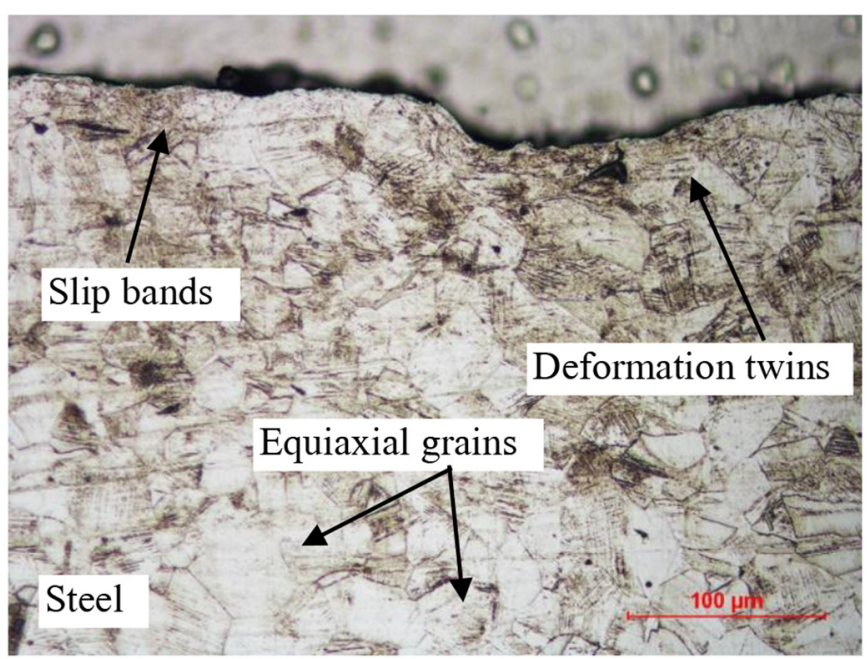

Fig. 3. Microstructure of stainless steel near the bond in specimen without the heat treatment.

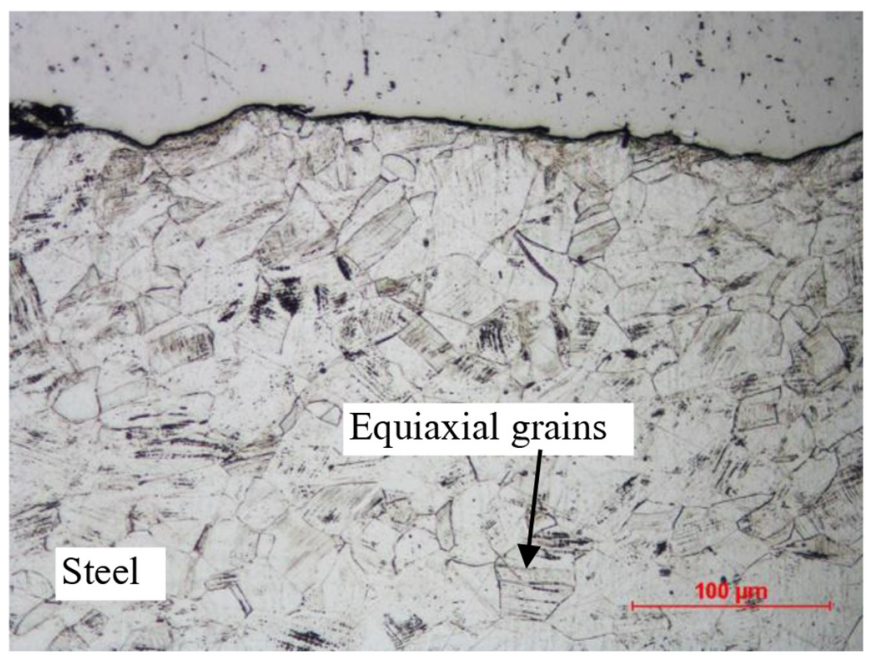

Fig. 4. Microstructure of stainless steel near the bond in specimen after the heat treatment.

showed at metallographic studies results in Figures 3-6. The microstructure of bond in bimetal without annealing is shown in Figure 3 and revealed equiaxed grains of stainless steel with many slip bands and deformation twins occurred on distance about $300 \mu \mathrm{m}$ from the bond, while further microstructure revealed typical grains of austenite. It was also observed that the grains adjacent to joint were strongly deformed and elongated in the direction of the explosion, parallel to the interface. This is consistent with an earlier study $[12,13]$. Presence of slip bands, elongated grains and twins is correlated with high plastic deformations caused by the high-velocity collision, which took place in the bonding interface during the explosion. Based on the microscopy analysis of heat-treated specimens it may be concluded that bond in the sample after the heat treatment exhibited significant changes of steel relative to the material before the heat treatment. The microstructure of stainless steel after the heat treatment is shown in

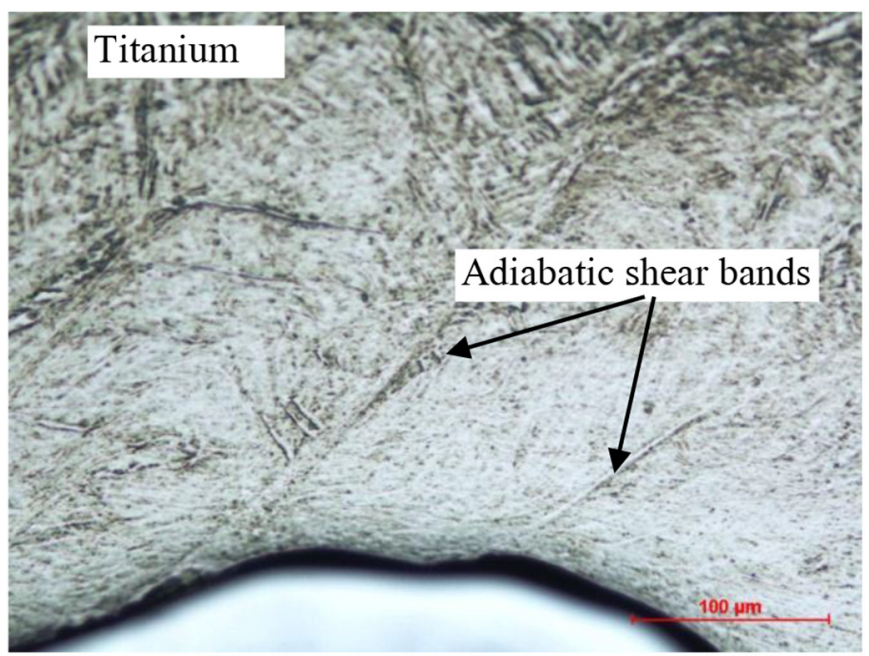

Fig. 5. Microstructure of titanium near the bond in specimen after the heat treatment.

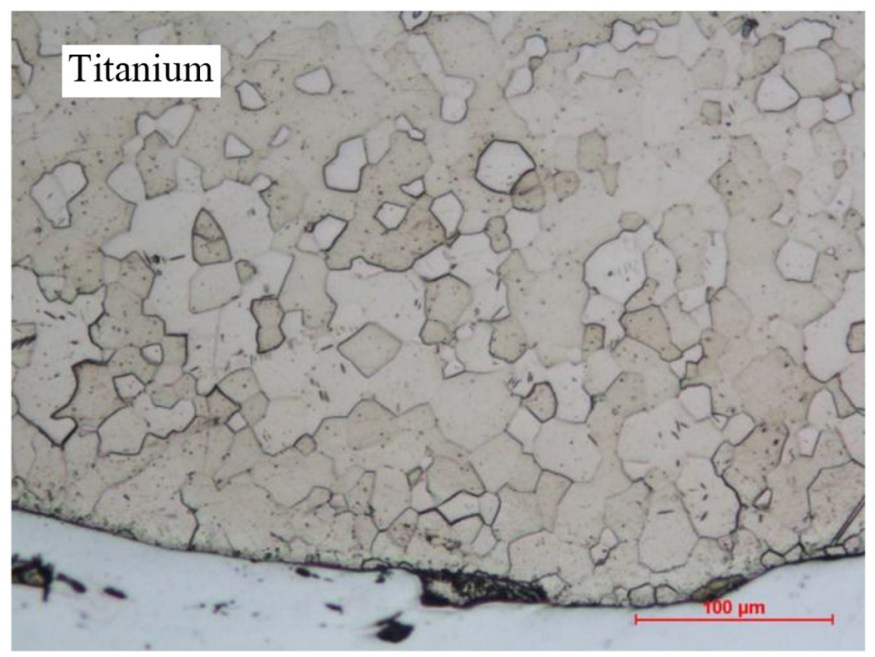

Fig. 6. Microstructure of titanium near the bond in specimen after the heat treatment.

Figure 4. After annealing grains near the joint has no deformations twins and slip bands, due to tempered character of heat treatment.

The microstructure of titanium adjacent to interface in bimetal without post-annealing (Fig. 5) demonstrated considerable grains deformation and presence of adiabatic shear bands (ASBs) occurred due to high velocity of process, which generate huge pressure in bonding area. Process of adiabatic shear band formation is correlated with high strain rate occurred in adiabatic conditions due to very short time of joining which lead to adiabatic temperature rise, forming and developing of ASB [14]. That phenomenon is characterized by highly localized large deformation. Deformation area with ASBs of titanium in bimetal without heat treatment has a length about $300 \mu \mathrm{m}$. In greater distance material revealed dynamic recrystallization, but enlarged grains have many deformation twins and slip bands. Changes for the titanium after annealing 

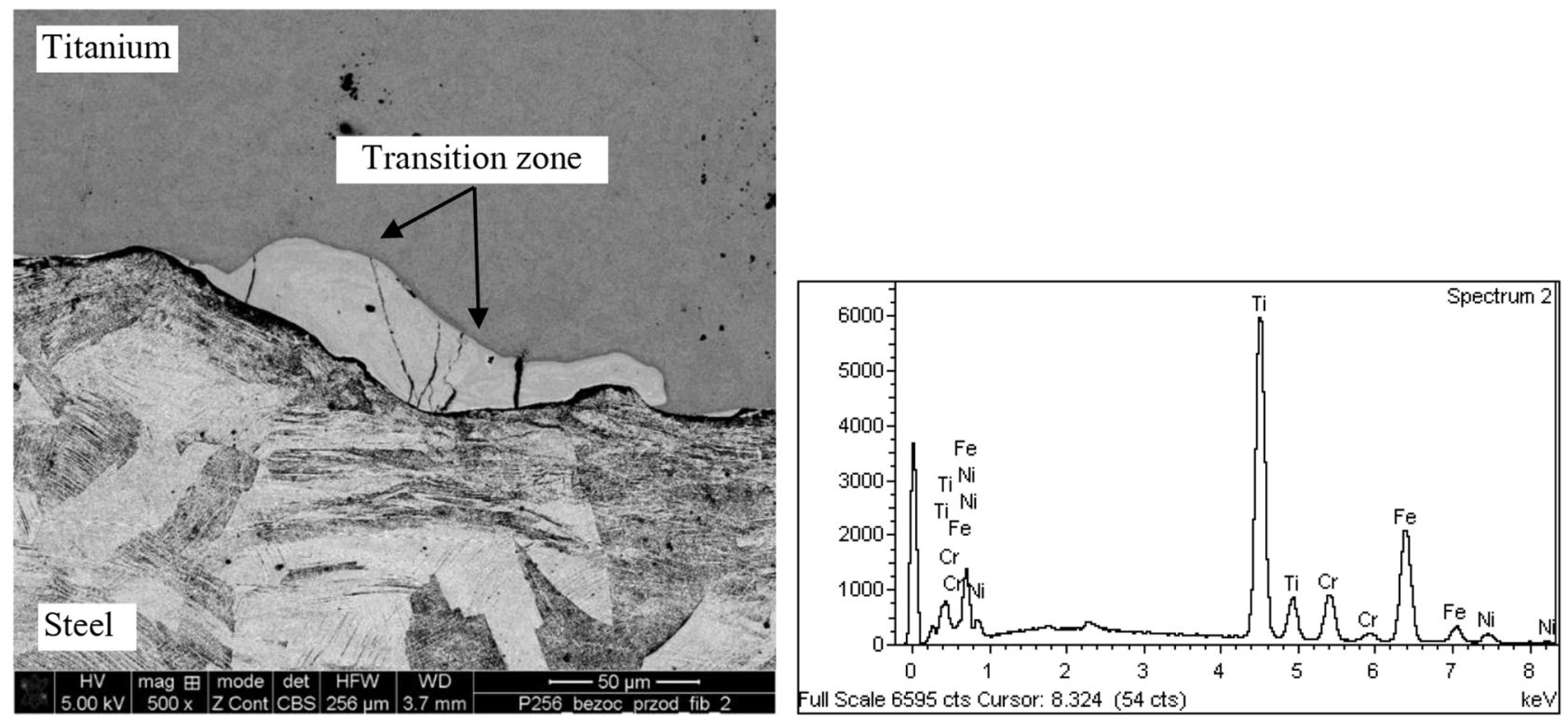

Fig. 7. SEM observation and EDS analysis of transition zone.

Table 3. Chemical composition of transition joint.

\begin{tabular}{llll}
\hline $\mathrm{Ti}$ & $\mathrm{Cr}$ & $\mathrm{Fe}$ & $\mathrm{Ni}$ \\
\hline \multicolumn{4}{c}{ [\% weight $]$} \\
45.68 & 10.11 & 39.16 & 5.04 \\
\hline
\end{tabular}

were more pronounced than in steel what is shown in Figure 6 . In this case, the heat treatment contributes to grains recrystallization near to interface and removing ASBs. Fine recrystallized grains have an average size of about $18.4 \mu \mathrm{m}$. In greater distance microstructure was recrystallized too, and the average grains size in this area was $50.2 \mu \mathrm{m}$.

Observation the boundary of welded metals revealed transitions zone adjacent to interface, what is shown in Figures 3 and 4 as a black linear structure. The transition area was observed both in bimetal before and after the heat treatment. It is a diffusion zone produced during joining the base and flyer material by the explosion, which is accompanied by huge pressure and temperature of the process. Due to hard conditions of welding, materials surfaces are melted and formed as a cracked, hard structure adjacent to joint. Back-scattered electron image of the interface in higher magnifications shown in Figure 7 exhibited differences in the chemical composition of melted area and native materials, what was confirmed by EDS analysis and submitted in Table 3. Based on chemical composition analyze results it may be concluded that the transition zone revealed a mixture of titanium and elements present in stainless steel $(\mathrm{C}, \mathrm{Fe}, \mathrm{Cr}, \mathrm{Ni})$. Moreover, SEM observations have shown the presence of the cracks in melted area. Cracked interface zone can have a negative influence on the durability of the bimetal, due to high microhardness about $1080 \mathrm{HV}_{0,1}$.

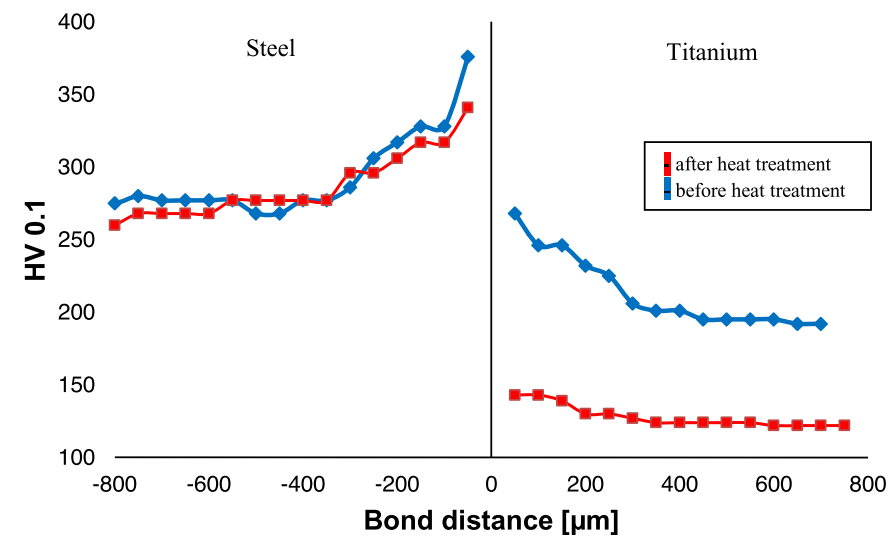

Fig. 8. Microhardness profile of explosively welded bimetal is state before and after the heat treatment.

The microhardness profile is shown in Figure 8. Depending on the microstructure, the microhardness test revealed significant growth of values in the deformation area both in steel and titanium, due to high strengthening on the interface. It was also observed that the maximum values of microhardness at joined materials without heat treatment was in the zone adjacent to joint and reached $376 \mathrm{HV}_{0,1}$ in steel and $268 \mathrm{HV}_{0,1}$ in titanium. Measurements exhibited that heat treatment caused relief of residual stresses and reduction of microhardness in the bond zone, hence maximum values in both material after annealing reached $341 \mathrm{HV}_{0,1}$ at steel side and $143 \mathrm{HV}_{0,1}$ in titanium. Reduction of microhardness after the annealing was more pronounced at the titanium than in steel. In distance greater than $300 \mu \mathrm{m}$ microhardness values both in $\mathrm{Ti}$ and steel were lower than near the boundary, what can be explained by a less influence of the explosion welding process in areas away from the interface. 


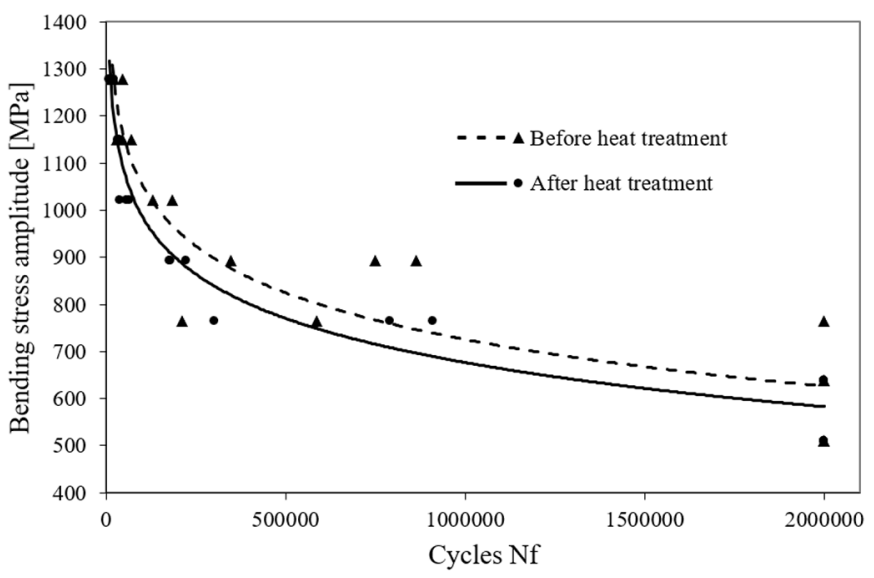

Fig. 9. Three-points bending test results graph.

In order to relate the microstructure observations with mechanical properties, three points bending tests were performed. Research results revealed decrease of fatigue strength after applied the heat treatment what is shown in Figure 9.

\section{Conclusions}

Current results have revealed the significant influence of applied post-heat treatment on microstructure and mechanical properties of explosively welded $316 \mathrm{~L} / \mathrm{cp}-\mathrm{Ti}$ bimetal used to production the sieve trays of heat exchangers. Changes observed in microstructure and microhardness measured after the heat treatment, confirmed that the application of the post-heat treatment is necessary to stress relief and normalize microstructure by grains recrystallization. Although, the effect such as residual stress relaxation and softening of the material are very favorable, the same heat treatment slightly reduces the fatigue strength of the joint.

Financial support of Research Statutory Program financed from Military University of Technology, Faculty of Civil Engineering and Geodesy: "Research of materials and construction elements of military infrastructure special objects", No. 886/2019 is gratefully acknowledged.

\section{References}

1. M. Wachowski, M. Gloc, T. Slezak, T. Płocinski, K.J. Kurzydłowski, The effect of heat treatment on the microstructure and properties of explosively welded titanium-steel plate, J. Mater. Eng. Perform. 26 (2017) 945-954

2. L. Č́žžk, D. Ostroushko, E. Mazancová, Z. Szulc, R. Molak, M. Wachowski, M. Praz mowski, Structure and properties of sandwich material steel $\mathrm{Cr} 13 \mathrm{Ni10}+\mathrm{Ti}$ after explosive cladding, Metall. J. 62 (2009) 110-112

3. P. Tamilchelvan, K. Raghukandan, K. Hokamoto, H.C. Dey, A.K. Bhaduri, Effect on explosive cladding of titan 12/ SS304L plates under multiple conditions (design matrix), Mater. Sci. Forum 207 (2004) 465-466

4. R. Kosturek, M. Wachowski, L. Sniezek, M. Gloc, The influence of the post-weld heat treatment on the microstructure of inconel 625 /carbon steel bimetal joint obtained by explosive welding, Metals 9 (2019) 246

5. L. Sniezek, I. Szachogluchowicz, M. Wachowski, J. Torzewski, J. Mierzynski, High cycle fatigue properties of explosively welded laminate AA2519/AA1050/Ti6Al4V, Proc. Struct. Integr. 5 (2017) 422-429

6. F. Findik, Recent developments in explosive welding, Mater. Des. 32 (2011) 1081-1093

7. V. Hutsaylyuk, L. Sniezek, M. Chausov, J. Torzewski, A. Pylypenko, M. Wachowski, Cyclic deformation of aluminium alloys after the preliminary combined loading, Eng. Fail. Anal. 69 (2016) 66-76

8. L. Bower, J. Banker, Large Titanium Heat Exchangers, Design, Manufacture and Fabrication Issues, in Proceedings of Corrosion Solutions, Conference 2003, Wah Chang

9. S.A.A. Akbari Mousavi, P. Farhadi Sartangi, Experimental investigation of explosive welding of cp-titanium/AISI 304 stainless steel, Mater. Des. 30 (2009) 459-468

10. R. Kacar, M. Acarer, An investigation on the explosive cladding of 316L stainless steel-din-P355GH steel, J. Mater. Process. Technol. 152 (2004) 92

11. ASTM A263-94a, Standard specification for corrosionresisting chromium steel-clad plate, sheet, and strip

12. B. Wronka, Testing of explosive welding and welded joints, Int. J. Impact Eng. 38 (2011) 309-313

13. N. Kahraman, B. Gülenc, F. Findik, Joining of titanium/ stainless steel by explosive welding and effect on interface, J. Mater. Process. Technol. 169 (2005) 127-133

14. Y. Yang, Z. Xinming, L. Zhenghua, L Qingyun, Adiabatic shear band on the titanium side in the $\mathrm{Ti} /$ mild steel explosive cladding interface, Acta Mater. 44 (1996) 561-565 